\title{
Safety aspects of Lactobacillus plantarum strains isolated from Siahmazgi cheese
}

\author{
Razieh PARTOVI ${ }^{1, a, ~}{ }^{凶}$, Hassan GANDOMI ${ }^{2, b}$, Afshin AKHONDZADEH BASTI ${ }^{2, c}$ \\ ${ }^{1}$ Amol University of Special Modern Technologies, Faculty of Veterinary Medicine, Department of Food Hygiene, Amol; \\ ${ }^{2}$ University of Tehran, Faculty of Veterinary Medicine, Department of Food Hygiene, Tehran, Iran. \\ a ORCID: 0000-0001-9930-0940; ' ${ }^{\mathrm{a} O R C I D: ~ 0000-0003-0846-6633 ; ~ ' ~} \mathrm{ORCID}$ : 0000-0001-7710-8966.
}

${ }^{\bowtie}$ Corresponding author: saboorapartovi@yahoo.com

Received date: 26.12 .2018 - Accepted date: 01.07.2019

\begin{abstract}
In order to use lactic acid bacteria as starter and non-starter cultures in fermentative products, their safety qualities should be evaluated. The objective of the present study was to evaluate safety characteristics including antibiotic sensitivity pattern, antimicrobial effect, $\mathrm{H}_{2} \mathrm{O}_{2}$ production, and biogenic amine production by Lactobacillus plantarum strains isolated from Siahmazgi cheese. Lactobacillus plantarum strains were unable to produce tyramine except for SD6 strain. All strains in the current study were able to produce histamine but unable to decarboxylate neither lysine nor ornithine. Lactobacillus plantarum strains showed considerable antimicrobial activity against Salmonella typhimurium and Listeria monocytogenes. All L. plantarum strains showed stronger antimicrobial activity against $S$. typhimurium $(3.5-42.55 \mathrm{~mm})$ than L. monocytogenes $(1.5-30.49 \mathrm{~mm})$. The SC9 strain had the strongest inhibitory effect against both pathogens. After titering $\mathrm{pH}$ of the medium to approximately 6.5 , no antimicrobial activity was noticed indicating that the antimicrobial activity of L. plantarum strains was contributed to their acid production and not to bacteriocin. All $L$. plantarum strains were capable of producing $\mathrm{H}_{2} \mathrm{O}_{2}$. SA32 and SD13 strains with 2.37 and $0.77 \mathrm{mmol} / \mathrm{L}$ were the strongest and the weakest strains regarding $\mathrm{H}_{2} \mathrm{O}_{2}$ production, respectively $(\mathrm{P}<0.05)$. All L. plantarum strains were sensitive to chloramphenicol, erythromycin, rifampicin, and tetracycline, yet resistant against vancomycin, and norfloxacin. Four patterns of antibiotic resistance were observed among L. plantarum strains. Only two strains of SC9 and SE4 were resistant against four antibiotics. L. plantarum strains naturally found in Siahmazgi cheese do not generally possess dangerous characteristics to be used in fermentative dairy products.
\end{abstract}

Keywords: Artisanal cheese, food safety, lactic acid bacteria, L. plantarum, Siahmazgi cheese.

\section{Introduction}

With respect to metabolic characteristics of lactic acid bacteria (LAB), they are used to improve the taste, texture, nutritional value, and safety of fermentative foods (38). Production of traditional fermentative products is dependent on spontaneous fermentation by wild LAB. Manufacturing such products in industrial scale and under hygienic conditions necessitates formulating a new set of specifically chosen strains as a starter culture which can guarantee the quality, safety, and consistency of the product (32).

In order to use starter and non-starter cultures in fermentative products, their safety qualities should be evaluated. Indiscriminate use of antibiotics is leading to resistance, mutations in the genes of microorganisms or resistance gene transformation from other bacteria (5). Antibiotic resistance is a serious concern today due to the risk of gene transformation from LAB to human pathogenic bacteria. Numerous studies have been conducted on antibiotic sensitivity/resistance of pathogenic bacteria so far $(12,16,26,33)$. Cataloluk and Gogebakan (5) showed that manually produced cheese contained the highest number of antibiotic resistant lactobacilli.

Many researchers have proven that the LAB will lengthen the shelf life and improve the safety of the product by restriction the growth of unfavorable microorganisms $(3,29,38)$. Some LAB produces metabolites (organic acids, $\mathrm{H}_{2} \mathrm{O}_{2}$, and bacteriocins) which act against bacteria including Escherichia coli, Staphylococcus aureus, and Salmonella species (14). LAB with ability to produce $\mathrm{H}_{2} \mathrm{O}_{2}$ restrict pathogens' growth in food and also can act as probiotic strains with beneficial health effects for consumers. Researchers have found a relationship between the presence of $\mathrm{H}_{2} \mathrm{O}_{2}$ producing Lactobacilli and decreased bacterial vaginosis, healing colitis and human immunodeficiency virus prevention $(14,36,40)$.

Decarboxylation of amino acids histidine, tyrosine, ornithine, and lysine will lead to biogenic amine production including histamine, tyramine, putrescine, and cadaverine. Production of excessive amounts of such substances will stimulate secretion of adrenalin and noradrenalin, stimulate gastric acid secretion, cause 
tachycardia and hypertension (10). In addition to all these, some people have histamine intolerance which causes diarrhea, headache, dizziness, cough, respiratory distress, hypotension, arrhythmia and heart rhythm disorders (17, $19,21)$. The ability of biogenic amine production by LAB need to be evaluated before they are used in foods so as to make it possible to evaluate freshness or spoilage of the product by measuring the concentration of these substances (19). Biogenic amine producing a capacity of Lactobacillus species is not considered as a legal criterion for the selection of species used as a starter or probiotic culture (7).

Siahmazgi cheese is an artisanal cheese produced from raw sheep and goat milk without addition of starter culture in the spring. The cheese ripens for a six month period in bags made of sheepskin called Khik and ripening is carried out by wild LAB normally found in raw milk, Khik or those naturally added to the product during handling in the production process. Partovi et al. (30) studied the microbial and chemical properties of Siahmazgi cheese for the first time and identified the majority of the LAB found using biochemical methods and 16s rDNA analysis. Lactobacillus plantarum was the major strain isolated from Siahmazgi cheese with $41.6 \%$ occurrence among the total LAB (34). Technological properties of $L$. plantarum strains isolated from Siahmazgi cheese have also been evaluated (31).

The objective of the present study is to evaluate safety characteristics including antibiotic sensitivity/ resistance pattern, antimicrobial effect, $\mathrm{H}_{2} \mathrm{O}_{2}$ production, and biogenic amine production by $L$. plantarum strains isolated from Siahmazgi cheese.

\section{Material and Methods}

Strains selection and preparation: Ten strains of $L$. plantarum were selected from the strains isolated from Siahmazgi cheese and were identified by means of biochemical tests and 16s rDNA analysis. The strains were lyophilized and stored in the Food Hygiene department of the Faculty of Veterinary Medicine of the University of Tehran (30).

Biogenic amine production: Moeller Decarboxylase broth base (Merck, Darmstadt, Germany) was used to evaluate biogenic amine production by $L$. plantarum strains. An amount of $1 \%$ amino acid (histidine, lysine, tyrosine and ornithine) was added to the medium and sterilized at $110{ }^{\circ} \mathrm{C}$ for 10 minutes. Bacterial culture (in De Man, Rogosa and Sharpe (MRS) broth (Merck, Darmstadt, Germany) at $30{ }^{\circ} \mathrm{C}$ for $48 \mathrm{~h}$ ) was used in order to inoculate the medium and the surface of the medium was covered with sterile liquid paraffin. Test tubes were then incubated at $30{ }^{\circ} \mathrm{C}$ for 1-4 days and evaluated daily. A control test tube was dedicated to each L. plantarum strain containing every item except the amino acid (20).

Antimicrobial activity: The antimicrobial activity of L. plantarum strains isolated from Siahmazgi cheese was evaluated using well diffusion method. Two reference strains (Listeria monocytogenes ATCC 7644 and Salmonella enterica subsp. enterica serotype Typhimurium (S. typhimurium hereafter) ATCC 14028) were used to check sensitivity to the antimicrobial substances produced by L. plantarum strains. Indicator strains were grown in Brain Heart Infusion (BHI) broth (Merck, Darmstadt, Germany) at $37{ }^{\circ} \mathrm{C}$ for $24 \mathrm{~h}$. These indicator strain cultures were added to sterile MRS agar $(100 \mu \mathrm{l} / \mathrm{L})$ and poured into petri-dishes. Then wells were made with a sterile pipette. L. plantarum strains were initially grown in MRS broth at $30{ }^{\circ} \mathrm{C}$ for $24 \mathrm{~h}$ and they were adjusted to $\mathrm{OD}_{600}=0.5$ and then $50 \mu \mathrm{l}$ of the cultures were added to the wells. The plates were held at $4{ }^{\circ} \mathrm{C}$ for $2 \mathrm{~h}$ and incubated at $30^{\circ} \mathrm{C}$ for $24 \mathrm{~h}$ and were subsequently examined for zones of inhibition. Then the diameter of inhibition zones ( $\mathrm{mm}$ ) around the agar wells were measured. Lactobacillus plantarum strains were cultured in MRS broth at $30{ }^{\circ} \mathrm{C}$ for $24 \mathrm{~h}$ and then centrifuged at $12000 \mathrm{~g}$ for 15 minutes to remove cells. The supernatant fluid was adjusted to $\mathrm{pH}=6.5$ with sterilized $1 \mathrm{~N} \mathrm{NaOH}$ and antimicrobial activity was checked by a well diffusion assay after excluding inhibition due to organic acids (8).

$\mathrm{H}_{2} \mathrm{O}_{2}$ production: In order to evaluate $\mathrm{H}_{2} \mathrm{O}_{2}$ production $(\mathrm{mmol} / \mathrm{L})$ by $L$. plantarum strains, $25 \mathrm{ml}$ of MRS broth supernatant from each strain was transmitted to $150 \mathrm{ml}$ flask. Twenty-five $\mathrm{ml}$ of newly made sulfuric acid was then added to it and tittered using $0.1 \mathrm{~N}$ potassium permanganate $\left(\mathrm{KMnO}_{4}\right)$. Becoming colorless is the end point of titration (13).

Antibiotic susceptibility: Disc diffusion method was used to evaluate antibiotic susceptibility of L. plantarum strains (8). Müller-Hinton medium (Merck, Darmstadt, Germany) with a pH value between 7.2 and 7.4 was used. Inoculation dose of each strain was initially calculated at the wavelength of $600 \mathrm{~nm}$ and then a microbial suspension containing $1 \times 10^{8} \mathrm{cfu} / \mathrm{ml}$ of $L$. plantarum was prepared. Antibiotic susceptibility test was then followed by inoculating the bacteria on the medium and antibiotic discs were placed on the medium using a sterile forceps $15 \mathrm{~min}$ after inoculation. The plate was then incubated at $30{ }^{\circ} \mathrm{C}$ for $48 \mathrm{~h}$ after which the diameter of growth inhibition area was measured in millimeters and the sensitivity of each strain against antibiotics was determined as sensitive, semi-sensitive, and resistant. The sensitivity of $L$. plantarum strains against 11 antibiotics chloramphenicol, gentamicin, vancomycin, ampicillin, penicillin, streptomycin, norfloxacin, erythromycin, rifampicin, tetracycline, and kanamycin was evaluated.

Statistical analysis: Analysis of variance (ANOVA test) with the Bonferroni test was used to determine significant differences in $\mathrm{H}_{2} \mathrm{O}_{2}$ production between different L. plantarum strains. All results were expressed as Mean \pm SD. Statistical analyses were performed using the SPSS version 22 software. $\mathrm{P}<0.05$ was considered as statistically significant. 


\section{Results}

Amino acid decarboxylation activity of L. plantarum strains has been shown in Table 1. L. plantarum strains isolated from Siahmazgi cheese were unable to produce tyramine except for SD6 strain. All strains in this study were able to produce histamine. L. plantarum strains were unable to decarboxylate either lysine or ornithine.

As it is depicted in Table 1, L. plantarum strains isolated from Siahmazgi cheese showed considerable antimicrobial activity against $S$. typhimurium and $L$. monocytogenes. All L. plantarum strains showed stronger antimicrobial activity against $S$. typhimurium (3.5-42.55 $\mathrm{mm})$ than L. monocytogenes (1.5-30.49 $\mathrm{mm})$. The SC9 strain had the strongest inhibitory effect against both pathogens with 49.5 and $55.5 \mathrm{~mm}$ of inhibition area for $L$. monocytogenes and $S$. typhimurium respectively. After tittering $\mathrm{pH}$ to approximately 6.5 , no antimicrobial activity was noticed indicating that the antimicrobial activity of $L$. plantarum strains was contributed to their acid production and that these strains were unable to produce bacteriocin.
All L. plantarum strains were capable of producing $\mathrm{H}_{2} \mathrm{O}_{2}$ (Table 1). There are significant differences among $L$. plantarum strains in the present study regarding $\mathrm{H}_{2} \mathrm{O}_{2}$ production $(\mathrm{P}$ value $=0.0001)$. SA32 and SD13 strains with 2.37 and $0.77 \mathrm{mmol} / \mathrm{L}$ were the strongest and the weakest strains regarding $\mathrm{H}_{2} \mathrm{O}_{2}$ production, respectively and were significantly different from other strains.

Antibiotic sensitivity profile of $L$. plantarum strains against 11 antibiotics is depicted in Table 2. All $L$. plantarum strains isolated from Siahmazgi cheese were sensitive to chloramphenicol, erythromycin, rifampicin, and tetracycline, yet resistant against vancomycin, and norfloxacin. Four patterns of antibiotic resistance were observed among L. plantarum strains (Table 3). Only two strains of SC9 and SE4 were resistant against four antibiotics which belong to vancomycin, streptomycin, norfloxacin, kanamycin and gentamicin, vancomycin, ampicillin, norfloxacin patterns, respectively and $50 \%$ of L. plantarum strains were resistant against three antibiotics vancomycin, norfloxacin and penicillin.

Table 1. Decarboxylation activity, $\mathrm{H}_{2} \mathrm{O}_{2}$ production and antimicrobial activity of $L$. plantarum strains isolated from Siahmazgi cheese against $L$. monocytogenes and $S$. typhimurium.

\begin{tabular}{|c|c|c|c|c|c|c|c|}
\hline \multirow{2}{*}{$\begin{array}{l}\text { Strains of } \\
\text { L.plantarum }\end{array}$} & \multicolumn{4}{|c|}{ Decarboxylation activity $^{*}$} & \multicolumn{2}{|c|}{ Antimicrobial activity $^{* *}$} & \multirow{2}{*}{$\begin{array}{c}\mathrm{H}_{2} \mathrm{O}_{2} \\
\text { production } \\
(\mathrm{mmol} / \mathrm{L})^{* * *}\end{array}$} \\
\hline & Ornithine & Tyrosine & Lysine & Histidine & L.monocytogenes & S.typhimurium & \\
\hline SC9 & - & - & - & + & 49.5 & 55.5 & $1.45 \pm 0.04^{\text {af }}$ \\
\hline SD6 & - & + & - & + & 34.7 & 54.5 & $1.90 \pm 0.01^{\mathrm{b}}$ \\
\hline SA32 & - & - & - & + & 37.5 & 49.5 & $2.37 \pm 0.09^{c}$ \\
\hline SC6 & - & - & - & + & 35.1 & 51.2 & $1.93 \pm 0.04^{\mathrm{bd}}$ \\
\hline SD5 & - & - & - & + & 35.3 & 55.2 & $1.86 \pm 0.04^{\mathrm{ab}}$ \\
\hline SC4 & - & - & - & + & 43.5 & 47.5 & $1.66 \pm 0.04^{\mathrm{bf}}$ \\
\hline SD13 & - & - & - & + & 32.6 & 45.2 & $0.77 \pm 0.04^{\mathrm{e}}$ \\
\hline SE4 & - & - & - & + & 31.1 & 42.3 & $1.27 \pm 0.20^{\mathrm{f}}$ \\
\hline SD11 & - & - & - & + & 30.1 & 51.2 & $1.76 \pm 0.09^{\mathrm{ab}}$ \\
\hline SD12 & - & - & - & + & 37.7 & 43.7 & $1.21 \pm 0.11^{\mathrm{f}}$ \\
\hline P-value & & & & & & & $<0.001$ \\
\hline
\end{tabular}

${ }^{*}+=$ positive; - = negative, ${ }^{* *}$ average diameter of growth inhibition zone of two replicates, ${ }^{* * *}$ Values are means \pm SD of two replicates, ***** The different superscripts $a, b, c, d, e, f$ in the same column indicate significant differences $(\mathrm{P}<0.05)$.

Table 2. Antibiotic sensitivity/resistance properties of L. plantarum strains isolated from Siahmazgi cheese.

\begin{tabular}{|c|c|c|c|c|c|c|c|c|c|c|c|}
\hline 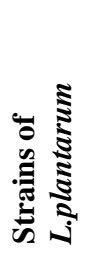 & 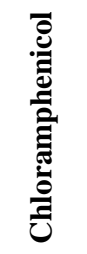 & 氖 & 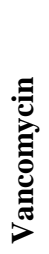 & 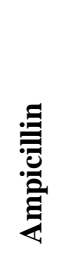 & 昜 & 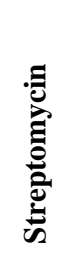 & 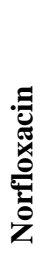 & 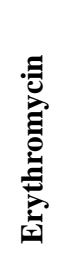 & : & 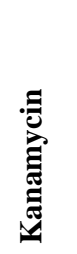 & 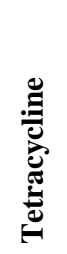 \\
\hline SC9 & $+++*$ & +++ & $\mathrm{R}$ & +++ & +++ & $\mathrm{R}$ & $\mathrm{R}$ & +++ & +++ & $\mathrm{R}$ & +++ \\
\hline SD6 & +++ & +++ & $\mathrm{R}$ & +++ & $\mathrm{R}$ & + & $\mathrm{R}$ & +++ & +++ & ++ & ++ \\
\hline SA32 & +++ & +++ & $\mathrm{R}$ & +++ & $\mathrm{R}$ & + & $\mathrm{R}$ & +++ & +++ & ++ & +++ \\
\hline SC6 & +++ & +++ & $\mathrm{R}$ & +++ & $\mathrm{R}$ & + & $\mathrm{R}$ & +++ & +++ & +++ & +++ \\
\hline SD5 & +++ & +++ & $\mathrm{R}$ & +++ & +++ & +++ & $\mathrm{R}$ & +++ & +++ & +++ & +++ \\
\hline SC4 & +++ & +++ & $\mathrm{R}$ & ++ & $\mathrm{R}$ & +++ & $\mathrm{R}$ & +++ & +++ & +++ & +++ \\
\hline SD13 & +++ & +++ & $\mathrm{R}$ & +++ & +++ & + & $\mathrm{R}$ & +++ & +++ & ++ & + \\
\hline SE4 & +++ & $\mathrm{R}$ & $\mathrm{R}$ & $\mathrm{R}$ & +++ & +++ & $\mathrm{R}$ & +++ & +++ & +++ & +++ \\
\hline SD11 & +++ & +++ & $\mathrm{R}$ & +++ & +++ & + & $\mathrm{R}$ & +++ & +++ & ++ & ++ \\
\hline SD12 & +++ & +++ & $\mathrm{R}$ & +++ & $\mathrm{R}$ & + & $\mathrm{R}$ & +++ & +++ & +++ & +++ \\
\hline
\end{tabular}

*++: 15-20 mm, ++: 10-14 mm, +: 1-9 mm, R: resistant. 
Table 3. Multiple drug resistance (MDR) patterns in L. plantarum strains isolated from Siahmazgi cheese.

\begin{tabular}{lc}
\hline MDR patterns & Percentage of resistant isolates $\mathbf{( \% )}$ \\
\hline Van/Str/Nor/Kan & 10 \\
Van/Pen/Nor & 50 \\
Van/Nor & 30 \\
Gen/Van/Amp/Nor & 10 \\
\hline
\end{tabular}

Van: vancomycin, Str: streptomycin, Nor: norfloxacin, Kan: kanamycin, Pen: penicillin, Gen: gentamicin, Amp: ampicillin

\section{Discussion and Conclusion}

Similar to the results of the current study, MorenoArribas et al. (24) and Landete et al. (18) reported that none of the $L$. plantarum strains were capable of producing putrescine or tyramine. Halasz et al. (11) showed that $20 \%, 40 \%$ and none of L. plantarum strains isolated from dairy products were capable of producing tyramine, cadaverine, and putrescine, respectively. A number of researchers have noticed considerable concentrations of histamine in Goda cheese which is presumably produced by the Lactobacilli in rennet (19). Lactobacillus acidophilus isolated from yoghurt in Nigeria possessed characteristics exactly contrary to those found in the L. plantarum strains in the current study as was capable of lysine, ornithine, and tyrosine decarboxylation but unable to produce histamine (27). This diversity in results regarding biogenic amine production suggests that this quality is strain dependent, and also it is affected by other factors including nutrient availability, production process, type of milk used, ripening time, growth condition, and $\mathrm{pH}(10,19)$. The inability to decarboxylate amino acids is a favorable quality in selecting strains as starter or adjunct cultures.

The SC9 strain had the strongest inhibitory effect against both pathogens. As it was stated in the previous study, SC9 strain was the strongest strain regarding acid production (31). The antimicrobial activity against $L$. monocytogenes is of paramount importance as this pathogen is ubiquitously found in the environment, and is resistant to refrigeration, acidity and high salt concentrations (29). A considerable number of listeriosis outbreaks worldwide have been contributed to raw milk and cheese consumption. The environment of ripened cheeses is suitable for the growth of L. monocytogenes because of lactate consumption by microorganisms and amine production and also increased $\mathrm{pH}$. Therefore, $L$. monocytogenes is considered a concern in cheeses such as Siahmazgi that undergo ripening for six months (28). Fifty-eight percent of $L$. plantarum strains isolated from fermented sausages showed antimicrobial effects against L. monocytogenes with growth inhibition areas of 2-10 $\mathrm{mm}$ of diameter (29). Klinberg et al. (15) and NietoLozano et al. (25) also have proven the antimicrobial activity of $L$. plantarum strains against $L$. monocytogenes. One of the most important pathways for Salmonella infection in human is consumption of raw milk or non- pasteurized dairy products (28). All $L$. plantarum strains isolated from traditional salted meat in Tunisia had antimicrobial activity against Staphylococcus aureus and S. enterica subsp. arizonae and most of them inhibited growth of E. coli and Pseudomonas aeruginosa (8). Contrary to the results of the present study, Nieto-Lozano et al. (25) showed that $L$. plantarum was ineffective against Salmonella species. The results of the current study verified those of Essid et al. (8) while are in contrast with those of Messi et al. (23) and Aymerich et al. (2) who have proven bacteriocin production by $L$. plantarum strains. Contrary to the results of the current study, Albano et al. (1) showed that L. plantarum strains are more effective against Gram positive than Gram negative bacteria, because bacteriocin producing strains are ineffective against Gram negative bacteria.

All L. plantarum strains isolated from Siahmazgi cheese were able to produce $\mathrm{H}_{2} \mathrm{O}_{2}$. SA32 strain with 2.37 $\mathrm{mmol} / \mathrm{L}$ was the strongest regarding $\mathrm{H}_{2} \mathrm{O}_{2}$ production. Sakamoto and Komagata (35) showed that $L$. delbrueckii subsp. delbrueckii produced up to $4.9 \mathrm{mmol} / \mathrm{L}$ of $\mathrm{H}_{2} \mathrm{O}_{2}$. $L$. acidophilus strains isolated from dairy products produced $1.62 \mathrm{mmol} / \mathrm{L}$ of $\mathrm{H}_{2} \mathrm{O}_{2}$ (6).

A significant number of strains of Lactobacillus salivarius, Lactobacillus casei, L. plantarum, Lactobacillus leichmannii, and L. acidophilus possess a gene causing natural resistance against vancomycin (22). In a study conducted by Beyan et al. (4) all $\mathrm{LAB}$ isolated from traditionally fermented milk were sensitive to penicillin and erythromycin. Beyan et al. (4) reported that $98.2 \%$ of the $\mathrm{LAB}$ strains isolated from traditionally fermented milk were sensitive to tetracycline and $80.7 \%$ were resistant against norfloxacin which showed significant similarity with the results of the current study. Lactobacillus plantarum strains isolated from raw camel milk were sensitive to tetracycline, vancomycin, erythromycin, ampicillin, kanamycin and resistant against rifampicin (9). Vancomycin is prescribed in the treatment of severe infections caused by Enterococcus and Staphylococcus species. Some Lactobacillus species including L. casei, Lactobacillus rhamnosus, Lactobacillus curvatus, L. plantarum, Lactobacillus coryniformis, L. brevis, and Lactobacillus fermentum are naturally resistant against vancomycin (42). Drug resistance can be transferred to other pathogens by transformation and conjugative plasmids or 
transposons in gastrointestinal tract $(34,37,39)$. It may become dangerous if there is the probability of resistance gene against vancomycin being transferred to Enterococcus species. Furthermore, some Enterococcus species possess the resistance gene against other antibiotics which may cause serious consequences in Enterococcus infections (42). This is not a concern per se, because these bacteria are sensitive to other antibiotics and have been safely used for long periods. The majority of $L$. plantarum strains in the current study were sensitive to most antibiotics. Absence of antibiotic resistance implies the absence of naturally occurring antibiotic resistance genes and also indicates that such genes have not been acquired by the bacteria from the environment (4). Generally, lactic acid bacteria isolated from dairy products show less commonly found antibiotic resistance in comparison to bacteria isolated from clinical or environmental sources (41).

Lactobacillus plantarum strains naturally found in Siahmazgi cheese do not generally possess dangerous characteristics to be used in fermentative dairy products. Considering that technological properties and safety aspects of $L$. plantarum strains from Siahmazgi cheese have been identified, it is recommended to produce fermented dairy products with original organoleptic properties using these strains as starter or adjunct cultures.

\section{Acknowledgments}

This research work has been supported by a research grant from Amol University of Special Modern Technologies.

\section{Conflict of Interest}

The authors are declared that there is no conflict of interest

\section{References}

1. Albano H, Oliveira M, Aroso R, et al (2007): Antilisterial activity of lactic acid bacteria isolated from "Alherias" traditional Portuguese fermented sausages: In situ assays. Meat Sci, 76, 796-800.

2. Aymerich MT, Garriga M, Monfort JM, et al (2000): Bacteriocin producing lactobacilli in Spanish-style fermented sausages: Characterization of bacteriocins. Food Microbiol, 17, 33-45.

3. Belgacem ZB, Abriouel H, Omar NB, et al (2010): Antimicrobial activity, safety aspects, and some technological properties of bacteriocinogenic Enterococcus faecium from artisanal Tunisian fermented meat. Food Control, 21, 462-470.

4. Beyan A, Ketema T, Bacha K (2011): Antimicrobial susceptibility pattern of lactic acid bacteria isolated from Ergo, a traditional Ethiopian fermented milk, Jimma, south west Ethiopia. Ethiopia J Edu Sci, 7, 9-17.
5. Cataloluk O, Gogebakan B (2004): Presence of drug resistance in intestinal lactobacilli of dairy and human origin in Turkey. FEMS Microbiol Lett, 236, 7-12.

6. Collins EB, Aramaki K (1980): Production of $\mathrm{H}_{2} \mathrm{O}_{2}$ by Lactobacillus acidophilus. J Dairy Sci, 63, 353- 357.

7. Costa MP, Rodriques BL, Frasao BS, et al (2018): Biogenic amines as food quality index and chemical risk for human consumption. 75-108. In: AM Holban, AM Grumezescu (Ed), Food Quality: Balancing Health and Disease, Handbook of Food Bioengineering. Academic Press, London, UK.

8. Essid I, Medini M, Hassouna M (2009): Technological and safety properties of Lactobacillus plantarum strains isolated from a Tunisian traditional salted meat. Meat Sci, 81, 203-208.

9. Fguiri I, Ziadi M, Atigui M, et al (2016): Isolation and characterization of lactic acid bacteria strains from raw camel milk for potential use in the production of fermented Tunisian dairy products. Int J Dairy Technol, 69, 103-113.

10. Garai G, Dueñas MT, Irastorza A, et al (2007): Biogenic amine production by lactic acid bacteria isolated from cider. Lett Applied Microbiol, 45, 473-478.

11. Halasz A, Barath A, Simon-Sarkadi L, et al (1994): Biogenic amines and their production by microorganisms in food. Food Sci Technol, 5, 42-49.

12. Hoge CW, Gambel JM, Srijan A, et al (1998): Trends in antibiotic resistance among diarrheal pathogens isolated in Thailand over 15 years. Clin Infect Dis, 26, 341-345

13. Horwitz W (1980): Official methods analysis of the Association of Official Analytical Chemists. 13th ed. Gaithersburg (MD): Association of Official Analytical Chemists.

14. Kang DK, Oh HK, Ham JS, et al (2005): Identification and Characterization of $\mathrm{H}_{2} \mathrm{O}_{2}$-generating Lactobacillus fermentum CS12-1. Asian-Australas J Anim Sci, 18, 90-95.

15. Klinberg TD, Axelsson L, Naterstad J, et al (2005): Identification of probiotic starter cultures for Scandinavian-type fermented sausage. Int $\mathrm{J}$ Food Microbiol, 105, 419-431.

16. Kothari A, Sagar V (2008): Antibiotic resistance in pathogens causing community-acquired urinary tract infections in India: a multicenter study. J Infect Dev Ctries, 2, 354-358.

17. Kovacova-Hanuskova E, Buday $\mathbf{T}$, Gavliakova $\mathbf{S}$, et al (2007): Histamine, histamine intoxication and intolerance. Allergol Immunopathol, 43, 498-506.

18. Landete JM, Ferrer S, Pardo I (2007): Biogenic amine production by lactic acid bacteria, acetic bacteria and yeast isolated from wine. Food Control, 18, 1569-1574.

19. Lorencová E, Buňková L, Matoulková D, et al (2012): Production of biogenic amines by lactic acid bacteria and bifidobacteria isolated from dairy products and beer. Int $\mathbf{J}$ Food Sci Technol, 47, 2086-2091.

20. Macfaddin JF (2000): Individual biochemical tests. 57-78. In: Macfaddin JF (Ed), Biochemical tests for identification of medical bacteria. Lippincott Williams \& Wilkins.

21. Maintz L, Novak N (2007): Histamine and histamine intolerance. Am J Clin Nutr, 85, 1185-1196.

22. Mathur S, Singh R (2005): Antibiotic resistance in food lactic acid bacteria. Int J Food Microbiol, 105, 281-295. 
23. Messi P, Bondi M, Sabia C, et al (2001): Detection and preliminary characterization of a bacteriocin (plantaricin 35d) produced by a Lactobacillus plantarum strain. Int $\mathbf{J}$ Food Microbiol, 64, 193-198.

24. Moreno-Arribas MV, Polo MC, Jorganes F, et al (2003): Screening of biogenic amine production by lactic acid bacteria isolated from grape must and wine. Int $\mathrm{J}$ Food Microbiol, 84, 117-123.

25. Nieto-Lozano JC, Reguera-Useros JI, Pélaez-Martinez, et al (2002): Bacteriogenic activity from starter cultures used in Spanish meat industry. Meat Sci, 62, 237-243.

26. Obst U, Schwartz T, Volkmann H (2006): Antibiotic resistant pathogenic bacteria and their resistance genes in bacterial biofilms. Int J Artif Organs, 29, 387-394.

27. Omafuvbe BO, Enyioha LC (2011): Phenotypic identification and technological properties of lactic acid bacteria isolated from selected commercial Nigerian bottled yoghurt. Afr J Food Sci, 5, 340 - 348.

28. Papademas P, Aspri M (2015): Dairy Pathogens: Characteristics and Impact. 69-114. In: Papademas P (Ed), Dairy Microbiology. CRC Press.

29. Papamanoli E, Tzanetakis N, Litopoulou-Tzanetaki E, et al (2003): Characterization of lactic acid bacteria isolated from a Greek dry-fermented sausage in respect of their technological and probiotic properties. Meat Sci, 65, 859-867.

30. Partovi R, Gandomi H, Akhondzadeh Basti A, et al (2015): Microbiological and chemical properties of Siahmazgi cheese, an Iranian artisanal cheese: isolation and identification of dominant lactic acid bacteria. J Food Process Preserv, 39, 871-880.

31. Partovi R, Gandomi H, Akhondzadeh Basti A (2018): Technological properties of Lactobacillus plantarum strains isolated from Siahmazgi cheese. J Food Process Preserv, 42, e13629.

32. Piraino P, Zotta T, Ricciardi A, et al (2008). Acid production, proteolysis, autolytic and inhibitory properties of lactic acid bacteria isolated from pasta filata cheeses: A multi-variate screening study. Int Dairy J, 18, 81-92.
33. Reacher MH, Shah A, Livermore DM, et al (2000): Bacteraemia and antibiotic resistance of its pathogens reported in England and Wales between 1990 and 1998: trend analysis. Br Med J, 320, 213-216.

34. Reenen CAV, Dicks LMT (2011): Horizontal gene transfer amongst probiotic lactic acid bacteria and other intestinal microbiota: what are the possibilities? A review. Arch Microbiol, 193, 157-168.

35. Sakamoto M, Komagata K (1996): Aerobic growth and activities of NADH oxidase and NADH peroxidase in lactic acid bacteria. J Ferment Bioeng, 82, 210-216.

36. Schellenberg JJ, Dumonceaux TJ, Hill JE, et al (2012): Selection, phenotyping and identification of acid and hydrogen peroxide producing bacteria from vaginal samples of Canadian and east African women. PLoS One, 7, e41217.

37. Scott KP (2002): The role of conjugative transposons in spreading antibiotic resistance between bacteria that inhabit the gastrointestinal tract. Cell Mol Life Sci, 59, 2071-2082.

38. Settanni L, Moschetti G (2010): Non-starter lactic acid bacteria used to improve cheese quality and provide health benefits. Food Microbiol, 27, 691-697.

39. Shao Y, Zhang W, Guo H, et al (2015): Comparative studies on antibiotic resistance in Lactobacillus casei and Lactobacillus plantarum. Food Control, 50, 250-258.

40. Singh AK, Hertzberger RY, Knaus UG (2018): Hydrogen peroxide production by lactobacilli promotes epithelial restitution during colitis. Redox Biol, 16, 11-20.

41. Suzzi G, Caruso M, Gardini F, et al (2000): A survey of the enterococci isolated from an artisanal Italian goat's cheese (semicotto caprino). J Applied Microbiol, 89, 267274.

42. Tynkkynen S, Singh KV, Varmanen P (1998): Vancomycin resistance factor of Lactobacillus rhamnosus $G G$ in relation to enterococcal vancomycin resistance (van) genes. Int J Food Microbiol, 41, 195-204 